\title{
MONOTONICITY PROPERTIES ON $k$-DIGAMMA FUNCTION AND ITS RELATED INEQUALITIES
}

\author{
EMRAH YILDIRIM
}

Abstract. In this work, we give some monotonicity properties of $k$-analogues of digamma and polygamma functions and then we obtain some inequalities related to these functions. At last, we give harmonic mean inequality for $k$-digamma function for all positive real values of $k$ and $x$.

Mathematics subject classification (2010): 26A48, 33B15, $26 \mathrm{D} 07$.

Keywords and phrases: $k$-polygamma function, $k$-digamma function, inequality, $k$-Binet's first formula for $\ln \Gamma_{k}(x)$.

\section{REFERENCES}

[1] M. Aldhaifallah, M. Tomar, K. S. Nisar and S. D. Purohit, Some new inequalities for $(k, s)$-fractional integrals, J. Nonlinear Sci. Appl., 9, (2016), 5374-5381.

[2] H. Alzer And G. Jameson, A harmonic mean inequality for the digamma function and related results, Rend. Semin. Mat. Univ. Padova. 137, (2017), 203-209.

[3] X. BAI, Y. Dong AND L. LIU, Completely monotonic functions and inequalities associated to some ratios of the Pochhammer $k$-symbol, J. Math. Anal. Appl., 432, 1, (2015), 1-9.

[4] N. BATIR, Sharp bounds for the psi function and harmonic numbers, Math. Inequal. Appl., 14, 4, (2011), 917-25.

[5] N. BATIR, Inequalities for the inverses of the polygamma functions, Arch. Math., 110, 6, (2018), 581-589.

[6] C. P. ChEN AND N. BATIR, Some inequalities and monotonicity properties associated with the gamma and psi functions, Appl. Math. Comput., 218, 17, (2012), 8217-25.

[7] R. Díaz And E. Pariguan, On hypergeometric functions and Pochhammer k-symbol, Divulg. Mat., 15, 2, (2007), 179-192.

[8] W. GAUTSCHI, A harmonic mean inequality for the gamma function, SIAM J. Math. Anal., 5, 2, (1974), 278-281.

[9] B. N. GUo AND F. QI, Refinements of lower bounds for polygamma functions, Proc. Amer. Math. Soc., 141, 3, (2013), 1007-1015.

[10] B. N. GUO, F. QI AND Q. M. LuO, The additivity of polygamma functions, Filomat, 29, 5, (2015), $1063-1066$.

[11] B. N. Guo, F. QI, J. L. ZHAO, AND Q. M. LuO, Sharp inequalities for polygamma functions, Math. Slovaca, 65, 1, (2015), 103-120.

[12] G. J. O. JAMESON, Convexity of $\Gamma(x) \Gamma(1 / x)$, Math. Inequal. Appl., 19, 3, (2016), 949-953.

[13] C. G. Kokologianna Ki, Properties and inequalities of generalized k-gamma, beta and zeta functions, Int. J. Contemp. Math. Sci., 5, 14, (2010), 653-660.

[14] V. KRASNIQI, Inequalities and monotonicity for the ration of $k$-gamma functions, Sci. Magna., 6, 1 , (2010), 40-45.

[15] S. Mubeen, S. IQbal And A. Rehman, Inequalities with applications involving $k$-beta random variable, J. Math. Inequal., 11, 3, (2017), 735-748.

[16] F. QI, R.Q. CUI, C.P. CHEN, B.N. GUO, Some completely monotonic functions involving polygamma functions and an application, J. Math. Anal. Appl., 310, 1, (2005), 303-308.

[17] F. QI, Bounds for the ratio of two gamma functions, J. Inequal. Appl., 2010, 1, (2010), 493058. 
[18] F. QI AND B. N. GuO, Some properties of extended remainder of Binet's first formula for logarithm of gamma function, Math. Slovaca, 60, 4, (2010), 461-470.

[19] F. QI, Limit formulas for ratios between derivatives of the gamma and digamma functions at their singularities, Filomat, 27, 4, (2013), 601-604.

[20] F. QI AND B. N. GUO, Integral representations and complete monotonicity of remainders of the Binet and Stirling formulas for the gamma function, Rev. R. Acad. Cienc. Exactas Fís. Nat. Ser. A Mat. RACSAM, 111, 2, (2017), 425-434.

[21] F. QI, A. AKKURT AND H. YILDIRIM, Catalan numbers, $k$-gamma and $k$-beta functions, and parametric integrals, J. Comput. Anal. Appl., 25, 6, (2018), 1036-1042.

[22] A. Rehman, S. Mubeen, N. SadiQ And F. Shaheen, Some inequalities involving k-gamma and $k$-beta functions with applications, J. Inequal. Appl., 2014, 1, (2014), 224.

[23] M. Z. SARIKAYA AND A. KARACA, $(k, s)$-Riemann-Liouville fractional integral and applications, Hacet. J. Math. Stat., 45, 1, (2016), 77-89.

[24] E. Set, M. Tomar AND M. Z. Sarikaya, On generalized Grüss type inequalities for $k$-fractional integrals, Appl. Math. Comput., 269, (2015), 29-34.

[25] E. Yildirim And İ. Ege, On k-analogue of digamma function, J. Class. Anal. 13, 2, (2018), $123-$ 131.

[26] L. Yin, L. G. Huang, X. L. Lin And Y. L. WAng, Monotonicity, concavity, and inequalities related to the generalized digamma function, Adv. Difference Equ., 2018, 1, (2018), 246.

[27] L. YIn, L. G. HuAng, Z. M. Song AND X. K. Dou, Some monotonicity properties and inequalities for the generalized digamma and polygamma functions, J. Inequal. Appl., 2018, 1, (2018), 249.

[28] E.T. WhitTAKeR AND G.N. WATson, A course of modern analysis, Cambridge University Press, Cambridge, 1996.

[29] J. ZHANG AND H. N. SHI, Two double inequalities for k-gamma and k-Riemann zeta functions, J. Inequal. Appl., 2014, 1, (2014), 191. 